\title{
Interação conteúdo e prática: uma contribuição para o ensino de estatística
}

\author{
Interaction content and practice: a contribution to the education of \\ statistics
}

\author{
Daiane Aparecida Miliossi Morais ${ }^{1}$ \\ Zenaide de Fátima Dante Correia Rocha ${ }^{2}$ \\ Leonardo Sturion ${ }^{3}$
}

\section{Resumo}

O ensino de estatística nas escolas públicas de Ensino Fundamental e Médio, geralmente vem sendo abordado no final do ano letivo de forma superficial. Em muitos casos em função da dificuldade de cumprir todos os programas estabelecidos nos cursos, estes conteúdos de estatística sequer são ministrados aos estudantes. Este estudo buscou compreender e aprimorar os saberes necessários para uma prática docente, baseada em uma experiência de ensino que abordou o conteúdo de estatística em uma escola pública do norte do Paraná, na qual a professora é uma das pesquisadoras. A metodologia adotada na pesquisa é de cunho descritivo com foco qualitativo, desenvolvida por meio de uma pesquisada própria prática. O curso realizado no ano de 2015, contou com a apreciação dos trabalhos de nove estudantes do segundo ano do ensino médio. A análise dos dados contou com registros dos sujeitos da pesquisa, nove estudantes e a professorapesquisadora, mediante áudio-gravação e anotações escritas dos estudantes. A interpretação dos dados basearam-se predominantemente na visão de Freire (1996), mais especificamente em sua obra, Pedagogia da Autonomia. Os resultados obtidos apontaram que uma prática docente fundamentada na mediação e criticidade estimulam e contribuem no processo de ensino e assimilação do conhecimento.

Palavras chave: Estatística; Saberes; Ensino.

\section{Abstract}

The statistical education in public schools of primary and secondary education, is generally being addressed at the end of the school year in a superficial way. In many cases due to the difficulty of fulfilling all programs established in the courses, these statistics contents are even taught to students. This study sought to understand and improve the knowledge needed for teaching practice, based on an educational experience that addressed the content statistics in a northern public schools of Paraná, where the teacher is one of the researchers. The methodology used in the research is of descriptive nature with qualitative focus, developed through a researched own practice. The course held in 2015, had the appreciation of the work of the nine students of second year of high school. Data analysis included records of

\footnotetext{
${ }^{1}$ daianemiliossi@gmail.com

2 zenaiderocha@utfpr.edu.br

3 leonardosturion@utfpr.edu.br
} 
the research subjects, nine students e the teacher-researcher by recording audio and written notes of students. The interpretation of the data were based predominantly in Freire's view (1996), more specifically in his work, Pedagogia da Autonomia. The results showed that a teaching practice based on mediation and stimulate critical and contribuemno teaching and assimilation of knowledge.

Keywords: Statistics; Knowledge; Education.

\section{Introdução}

A atividade de fazer uma pesquisa segundo Prodanov e Freitas (2013, p. 43) consiste em "procurar respostas para indagações propostas. Podemos dizer que, basicamente, pesquisar é buscar conhecimento.". Logo, o objetivo principal de uma pesquisa é ampliar ou adquirir algum conhecimento.

A pesquisa voltada para a educação segue o mesmo princípio no sentido de acompanhar todas as evoluções que acontecem ao longo do tempo, ou seja, prioriza-se o processo em detrimento do produto,fato que pode colocar o "pesquisador no meio da cena investigada, participando dela e tomando partido na trama da peça" (LÜDKE, ANDRÉ, 2013, p. 8).

O presente artigo consiste em uma pesquisa, voltada à análise de como o conteúdo de estatística aplicado à realidade do estudante pode contribuir no processo de ensino e aprendizagem, bem como trazer melhorias para o ambiente em que está inserido.

Elaborado a partir de uma proposta de avaliação parcial de uma disciplina do Mestrado Profissional em Ensino de Matemática, da Universidade Tecnológica Federal do Paraná, campus Londrina, intitulada Saberes Docentes e Formação Profissional.

Este trabalho buscou investigar em que medida a interação teoria e prática no ensino de estatística, poderá contribuir para a aprendizagem de estudantes do Ensino Médio e as mudanças que podem ocasionar, quando o conteúdo trabalhado reflete diretamente no cotidiano destes sujeitos.

\section{METODOLOGIA DE PESQUISA}

Esta pesquisa é de natureza qualitativa, tratando-se de uma pesquisa da própria prática, na qual o pesquisador e os pesquisados trabalharam juntos na elaboração de conceitos de estatística, na discussão das estratégias adotadas perante à análise dos resultados obtidos em um trabalho intitulado de "Oficina de estatística básica".

A pesquisa foi realizada em uma escola estadual na cidade de Cambé, com dezesseis estudantes do segundo ano do ensino médio. O convite para participar do trabalho foi estendido a todos os estudantes desta série e depois houve a seleção usando os critérios de melhores notas, pois tiveram trinta interessados e a sala de informática só comportava dezesseis estudantes. Ao todo foram realizados três encontros em período contraturno com duração média de duas horas cada. No primeiro encontro foram doze estudantes e nos demais nove.

Foi considerada no processo de análise a produção dos nove estudantes que participaram de todas as aulas. Como forma de preservar a identidade dos mesmos, as falas foram relatas como $E_{1}$ (estudante1), $E_{2}$ (estudante 2), e assim sucessivamente até $E_{9}$ 
(estudante 9), não se preocupando com a identificação desses sujeitos, pois a intenção está nas interações e questionamentos gerais dos estudantes.

A "Oficina de estatística básica" teve como objetivo ensinar alguns conceitos de estatística trabalhando com dados do contexto escolar, gerando com isso uma discussão de melhorias, para a escola em questão. Para isso, as análises foram realizadas tomando como foco as notas obtidas pelos estudantes do segundo ano do ensino médio no primeiro trimestre do ano de 2015, com o objetivo de buscar alternativas que pudessem melhorar o desempenho dos mesmos e de seus colegas de classe nos próximos trimestre.

Este trabalho de reflexão sobre o rendimento escolar já era realizado no colégio, porém de forma simples, onde era apresentado aos estudantes somente um gráfico de colunas com a quantidade de estudantes que estavam abaixo da média em cada uma das disciplinas. Logo, por meio da oficina foi possível elaborar um estudo mais aprofundado sobre a situação em que cada classe do segundo ano se encontrava, de modo geral, e em cada uma das disciplinas.

Os dados foram coletados durante todo o processo de aplicação e discussão da oficina, por meio de gravações de áudio, análise dos materiais elaborados pelos estudantes e registros da professora.

A metodologia de análise adotada neste projeto é de cunho descritivo qualitativo, definida por Prodanov e Freitas (2013), como qualitativa a pesquisa na qual o ambiente é a fonte dos dados, não permitindo qualquer manipulação dos mesmos pelo pesquisador, e descritiva aquela que relata a maior quantidade de elementos presentes no foco da investigação. Neste projeto buscou-se enfatizar por meio desta metodologia a interação da aprendizagem dos estudantes e a prática da professora pesquisadora.

\section{REFERENCIAL TEÓRICO}

A base de reflexão deste trabalho tem por fundamento a pedagogia histórico-crítica, que na concepção de Vygotsky, considera a aprendizagem como um processo interno, ativo e interpessoal que interliga a aprendizagem e o desenvolvimento, em que o papel do professor é o de mediar o conhecimento (NEVES, DAMIANI, 2006). Para Freire (1996), é imprescindível que os educadores considerem e compreendam os saberes que são indispensáveis para uma prática docente, partindo deste pressuposto, será realizada uma análise da percepção concebida pelos estudantes durante a realização do projeto e também da professora como condutora do mesmo, pretendendo aprimorar e desenvolver estes saberes.

A análise da visão do estudante será em relação ao conteúdo abordado, sua expectativa e reflexão sobre o que foi estudado, basear-se-á nos apontamentos levantados por eles durante a atividade e diante dos resultados obtidos. Em relação à professora consistirá em uma analise didática sobre o modo de condução da aula e do conteúdo, e também de apontamentos que provocaram uma reflexão de sua conduta de ensino.

É importante considerar que "ensinar é perseguir fins, finalidades. Em linhas gerais, pode-se dizer que ensinar é empregar determinados meios para atingir certas finalidades" (TARDIF, 2013, p. 125), pensando por esta perspectiva, o professor quando propõe algo aos estudantes, teve a priori a preocupação com o objetivo que pretende atingir, isto foi levado em consideração durante a elaboração da oficina, de forma a permitir que os educandos 
pudessem exprimir suas ideias, levantar hipóteses, fazer conjecturas refletindo sempre por meio dos conhecimentos cognitivos adquiridos anteriormente.

Segundo Tardif,

"os professores não buscam somente realizar objetivos; eles atuam, também sobre um objeto. O objeto de trabalho dos professores são seres humanos individualizados e socializados ao mesmo tempo. As relações que eles estabelecem com seu objeto de trabalho são portanto, relações humanas, relações individuais e sociais ao mesmo tempo" (TARDIF, 2013, p. 128).

Portando, é importante que o professor compreenda que cada estudante tem uma característica própria, são distintos entre si, e isto não difere no processo de aprendizagem, necessitando que esta disparidade seja considerada durante toda a ação.

Para que se consiga atingir uma aprendizagem efetiva, perante esta ambiguidade de sujeitos é importante que o professor "reflita e realinhe sua prática pedagógica no sentido de criar possibilidades para instigar a aprendizagem do aluno" (BEHRENS, 2013, p. 78) e com isso atinja se objetivo principal que é a formação de cidadãos críticos e reflexivos.

A formação como um todo, exige que o professor possibilite que haja uma ponte entre a questão teórica e a prática, para que isto ocorra é necessário que o mesmo permita que durante as aulas os estudantes possam discutir, questionar e formar hipóteses. Portanto, "a reflexão crítica sobre a prática se torna uma exigência da relação Teoria/Prática sem a qual a teoria pode ir virando blablabla ${ }^{4}$ e a prática, ativismo". (FREIRE, 1996, p. 12). Reforçando mais uma vez a importância da reflexão do professor.

Esta reconstrução da prática pedagógica exige que haja um momento de replanejamento, de vivência, de troca de experiências e busca pessoal, pois "ninguém pode aprender da experiência do outro" (BONDÍA, 2002, p. 27).

A reflexão sobre a prática pedagógica, segundo Freire (1996) vem sendo muito discutida na área de educação desde a formação, a fim de que o professor compreenda que ensinar é criar possibilidades para que o conhecimento seja construído e não somente transferido para o estudante. Pensando sempre num conjunto que não pode ser dissociado, visto que,"não há docência sem discência, [...], quem ensina aprende ao ensinar e quem aprende ensina ao aprender" (FREIRE, 1993, p. 12).

Ainda de acordo com Freire (1993), o educador, em sua prática docente, deve reforçar a capacidade crítica do educando, aumentando sua curiosidade, possibilitando que ensino não se restrinja somente o conteúdo, mas permita que os educando pensem, desenvolvendo a capacidade de construir e reconstruir o saber ensinado.

Para que o educador tenha todos os atributos necessários no momento de transmitir seu conhecimento, ele precisa conceber uma prática docente crítica, que "envolve o movimento dinâmico, dialético, entre o fazer e o pensar sobre fazer" (FREIRE, 1993, p. 17), envolve o repensar antes de fazer algo, pois "é pensando criticamente a prática de hoje ou de ontem que se pode melhorar a próxima prática". (FREIRE, 1993, p. 18).

Conceber um profissional reflexivo é uma das premissas presentes nos educadores que pesquisam sua própria prática, a pesquisa segundo Ponte (2004,p. 5) "é um processo

\footnotetext{
${ }^{4}$ Terminologia usada pelo autor
} 
fundamental de construção do conhecimento que começa com a identificação de um problema relevante - teórico ou prático - para qual se procura, de forma metódica, uma resposta convincente que se tenta validar e divulgar", vendo por este perfil, a pesquisa permite que o professor verifique quais estratégias precisam ser aprimoradas e desenvolvidas em seu processo de ensinar.

Partindo deste pressuposto, o trabalho aqui exposto caracteriza-se como uma pesquisa da própria prática, definida por Ponte (2004, p. 5), como uma pesquisa onde "o pesquisador tem uma relação muito especial com o objeto de estudo - ele não estuda um objeto qualquer, mas sim um aspecto da sua própria prática profissional", neste caso, o professor pesquisador, pretende verificar sua prática de ensino e o aprendizado de seus estudantes segundo a visão de Freire (1993).

Levando em consideração todos os requisitos necessários de ensino abordados por Freire (1993), o tema escolhido para a oficina foi um que permitisse que os estudantes pudessem utilizar seus conhecimentos prévios, formular proposições, tirar conclusões e ao mesmo tempo tivessem a oportunidade de intervir em seu meio escolar.

Ao realizar uma varredura nos Parâmetros Curriculares Nacionais do Ensino Médio PCN (2000) foi possível verificar que é necessário que se desenvolva algumas competências e habilidades nos estudantes, dentre elas estão: "Ler, interpretar e utilizar representações matemáticas (tabelas, gráficos, expressões, etc.). Utilizar adequadamente os recursos tecnológicos como instrumentos de produção e de comunicação". (BRASIL, 2000, p. 46)

Indo ao encontro com os PCNs, as Orientações Curriculares para o Ensino Médio Ciências da Natureza, Matemática e suas Tecnologias (2006), relatam que abordar conteúdos estatísticos no ensino médio,
"viabiliza a aprendizagem da formulação de perguntas que podem ser respondidas com uma coleta de dados, organização e representação. [...] Recomenda-se um trabalho com ênfase na construção e na representação de tabelas e gráficos mais elaborados, analisando sua conveniência e utilizando tecnologias, quando possível. Problemas estatísticos realísticos usualmente começam com uma questão e culminam com uma apresentação de resultados que se apoiam em inferências tomadas em uma população amostral." (BRASIL, 2006, p. 78)

Consonante com esta perspectiva, e levando em consideração o pensamento de Alsina (2009), de que é necessário que os estudantes tenham consciência dos conhecimentos matemáticos que tiveram aquisição, e esta percepção é adquirida por meio da utilização de situações reais na realização das atividades. Buscou-se elencar conceitos básicos de estatística utilizando uma abordagem diferente da tradicional, conciliando o uso da tecnologia e uma base de dados do contexto escolar, a fim de que a professora pesquisadora encontrasse meios para analisar quais reflexos foram mais marcantes na posição dos estudantes e em sua prática docente.

Costumeiramente, os estudantes podem até pensar matematicamente, mas não fazem reflexão daquilo que estudaram, segundo Bicudo (2005) não se pode ter a clareza imediata daquilo que se aprende sem um trabalho pessoal do estudante, sem o exercício sistemático de pensar. Portanto, é de suma importância que o educando participe ativamente do processo de ensino e aprendizagem, para que a transmissão do conhecimento ocorra.

O objetivo de conciliar a teoria com dados do ambiente escolar, permite que o estudante reflita e produza significado ao que esta estudando, possibilitando que os 
mesmos aprendam e consigam aplicar o aprendizado em seu cotidiano, gerando mudanças no meio que vive, visto que "a educação é uma forma de intervenção no mundo". (FREIRE, 1996, p.38)

Para atingir este objetivo é necessário que o professor tenha em mãos os mais variados recursos e estratégias de ensino, buscando dar não somente significado para o que se é estudado mediante aplicação e utilidade do conteúdo teórico, mas também levando o estudante a pensar criticamente, a levantar hipóteses e a buscar soluções para os problemas que encontra em seu cotidiano.

Esta visão de aprendizado reflete em uma mudança no papel do professor, que além de buscar alternativas pedagógicas deve refletir sobre como pode contribuir para que seus estudantes pensem e tirem conclusões sobre o que está sendo ensinado, levando em consideração os anseios e desejos dos mesmos, pois "a sabedoria do mestre revela uma grandiosidade: o desejo de aprender com seu aluno." (TIBA, 1998, p 66).

Acerca de tudo isto se revela a necessidade de que o professor ouça, dialogue e reflita sobre o que seu estudante esta dizendo, proporcionando assim uma mudança na concepção de ensinar e de aprender, e nada melhor para que isto aconteça do que uma pesquisa de sua própria prática.

\section{DESCREVENDO A OFICINA}

A oficina teve início com a seguinte pergunta:

O que você entende por estatística?

Diante da questão os estudantes ficaram parados, esperando que a professora iniciasse alguma definição ou falasse o que deveria ser feito, fato que a deixou surpresa. Suas alegações eram no sentido de que não sabiam nada sobre o tema, logo não poderiam escrever a respeito. Mesmo assim, a professora insistiu:

Professora: Escrevam o que vocês pensam que seja estatística. O objetivo aqui não é avaliar se está certo ou errado, é ver aquilo que vocês já sabem.

A partir disto eles começaram a escrever, mesmo aparentando estar bem receosos, com medo de estarem errados.

As respostas mais interessantes que vale destacar foram:

$E_{1}$ : Estatística é a área da matemática relacionada à análise e obtenção de dados. Pode ser através de tabelas, gráficos e etc.

$\mathrm{E}_{2}$ : Uma pesquisa.

$E_{3}$ : Acho que é algo que mexe com gráfico, notas e números, não entendo muito bem por isso comecei a fazer o curso.

E6: É utilizado para montar dados e mostrar a situação.

$E_{7}$ : Eu acho que seria uma coisa que ajuda a você calcular, é bastante utilizado em empresas. 
Pode-se perceber que a maioria deles achava que não sabia nada sobre o que iria estudar, mas conforme foram dialogando e colocando seus pensamentos, perceberam que todos sabiam algo sobre o conteúdo, o que gerou um maior entusiasmo no início, sentiram-se mais motivados. Isto vem ao encontro com o pensamento de Behrens (2013), de que o papel do professor consiste em criar possibilidades para instigar a aprendizagem do estudante.

Depois do primeiro contato sobre o tema da oficina, eles tiveram a leitura de um pequeno texto falando da história da estatística, com a finalidade de compreenderem como surgiu e como foi evoluindo com o passar do tempo.

Em um segundo momento da oficina, eles assistiram a um vídeo que falava sobre população e amostra, construíram os conceitos individualmente e em seguida realizaram a discussão no grupo a fim estabelecerem um conceito único no grupo.

A importância da discussão em grupo possibilita que os estudantes aprendam a ouvir as opiniões dos demais, fortalecendo a comunicação entre eles e a capacidade de expor seus apontamentos, visto que de acordo com Freire (1996), ensinar exige que se saiba escutar, não deve ser algo verticalizado, onde o professor fala e os estudantes escutam, para tanto é necessário que haja a abertura para a troca e diálogo mútuo.

Dando continuidade a oficina, a professora fez o seguinte questionamento:

Professora: Antes de continuarmos pensem um pouco sobre estas perguntas:

O que média? O que é moda? O que é mediana?

Como vocês responderiam estas questões?

Estas perguntas provocaram instabilidade em alguns estudantes, ficando evidente 0 medo que eles têm de errar, podendo-se destacar os seguintes comentários:

E7: Eu não sei nada disso professora, não sei nem começar a responder.

Professora: Tem certeza de que não sabe nada?

$E_{7}$ : Tenho! Só sei que média é uma coisa que não é tão grande, nem tão pequena, tá na média.

Professora: E porque você não coloca isso no papel?

$E_{7}$ : Porque está errado!

Professora: Coloque o que você sabe, não está perguntando como você responderia, não tenha medo de colocar o que você pensa.

Depois desta discussão, o estudante colocou no papel seu pensamento, mas questionou novamente:

E7: Professora, de moda eu só sei de roupa!!! (rindo)

Professora: E o que acontece quando uma roupa está na moda?

E7: Todo mundo usa, ué. 
Professora: Se todo mundo usa, aparece pouco? É difícil de encontrar?

$E_{7}$ : Não, está em todo lugar.

Professora: E como você disse que não sabe o que é moda? Pensa na matemática, o que pode ser uma moda?

$\mathrm{E}_{7}$ : É o que aparece mais?

Professora: Anote ai, o que você acha depois vamos fazer a discussão com as respostas dos outros.

Ainda com medo do erro o mesmo estudante perguntou sobre a última questão apresentada pela professora.

$\mathrm{E}_{7}$ : E mediana professora? Nunca vi isso!

Professora: Se eu disser a você, que uma pessoa é mediana, o que você entenderia?

$E_{7}$ : Que ela não é ruim, mas também não é boa, tá no meio termo.

Professora: Tá vendo como você sabe, quem disse que não está correto?

E7: Nossa professora, é isso! Nossa e eu estava com medo de errar.

Diante das falas deste estudante, pode-se perceber que eles não estão acostumados a utilizar seus conhecimentos prévios no processo de aprendizagem, aparentemente têm demonstrado a necessidade da aprovação da professora, o que os tornam inseguros diante de tal proposta, porém é necessário que isto deixe de causar estranheza e passe a ser comum dentro do ambiente escolar, uma vez que "ensinar exige respeito as saberes dos educandos" (FREIRE, 1996, p. 15), tanto em questões mais simples como foi proposto, quanto em questões de cunho sociais.

Ao concluírem suas suposições, explanaram para os demais integrantes do grupo e com a intervenção da professora construíram um conceito mais formal sobre as medidas de tendências propostas.

Para exercitarem o conhecimento construído, a professora propôs que, agrupados em trios ou duplas, encontrassem as três medidas de posição, tendo como dados um quadro de notas da disciplina de matemática de uma das turmas no primeiro trimestre.

Diante do proposto, algo interessante aconteceu, como eles estavam no laboratório de informática, um dos estudantes ligou o computador, abriu a ferramenta "calc" e começou a digitar os dados.

Professora: Porque vocês estão usando o computador?

$E_{1}$ : Fica mais fácil de organizar os dados, professora! Não pode?

Professora: Pode sim, se você acha assim mais fácil, não tem problema.

Quando os demais perceberam a ideia do colega resolveram fazer o mesmo, antecipando o que a professora iria propor num segundo momento. No entanto, algo 
chamou a atenção, os estudantes apresentaram muita dificuldade em realizar comandos básicos, que no caso era apenas organizar os dados de forma crescente, podendo-se constatar que, mesmo usando a internet, computador, tablets no dia a dia, a utilização de softwares com fins educativos é pouco ou quase nada utilizadas, eles não tinham familiaridade com aquele instrumento. Portanto, a oficina possibilitou que fosse atingida uma das propostas presentes nos PCNs (2000), que consiste na utilização dos recursos tecnológicos para dinamizar o processo de ensino.

Depois de todos os cálculos a professora propôs que houvesse um debate.

Professora: Bom, agora que todos encontraram o que foi pedido, o que podemos concluir sobre a disciplina de matemática desta turma?

Eg: No geral as notas desta turma de matemática estão acima da media escolar que é 6,0. (falando da média encontrada)

E: Que a maioria das notas não está tão ruim. (falando da moda)

$E_{1}$ : Que $50 \%$ da turma está com uma nota acima da média. (relacionado à mediana)

Com a finalidade de continuar o debate e ver as propostas que os estudantes apresentariam a professora fez a seguinte pergunta:

Professora: O que é preciso fazer para que este quadro de notas melhore?

$E_{1}$ : Olha professora, do jeito que eles levam o gráfico de notas pra gente eu achei que a situação era bem pior. Tem que melhorar a forma de apresentar. ${ }^{5}$

$E_{2}$ : É verdade professora, desanima ver aquilo, eu achei que a gente ia achar uma coisa bem pior.

As falas dos estudantes vieram ao encontro da próxima atividade da oficina, que se baseava em realizar uma análise de todas as notas do primeiro trimestre, nas três classes.

Diante do discurso proferido pelos estudantes, pode-se perceber que na visão dos mesmos,o modo que o quadro de notas estava sendo demonstrado na sala de aula não favorecia uma melhora, pelo contrário, desestimulava.

Assim, os estudantes dividiram-se em três grupos, ficando cada um responsável pelo cálculo, interpretação, construção de gráficos de barras de cada disciplina e análise dos dados, para que posteriormente propusessem algo que melhorasse o desempenho daquela turma.

Cada grupo realizou os cálculos e expôs para os demais suas análises:

$E_{2}$ : Nossa professora, português está muito ruim, tem metade dessa sala para baixo de $6,0{ }^{6}$

${ }^{5}$ O estudante se referiu a um gráfico de notas que a escola apresenta no final de cada trimestre, onde consta a quantidade de notas vermelhas em cada uma das disciplinas. 
E7: Esse gráfico ajuda a ver que nem sempre é tão ruim quanto parece.

$\mathrm{E}_{8}$ : Nossa, metade da turma tem mais nota que 7,4. (referindo-se à matéria de inglês)

$E_{1}$ : Assim dá pra ver a área que tem mais dificuldade, professora, e pensei que era só exatas, não é não.

Após a discussão em sala, um grupo se propôs a falar sobre a oficina para a equipe pedagógica, a fim de explicar os resultados obtidos e propor as melhorias que achavam necessárias.

De acordo com Freire (1996), a educação deve ser um processo de intervenção no mundo, dentro e fora das escolas, esta atividade permitiu que os estudantes tivessem subsídios para propor mudanças e alternativas de melhorias dentro do ambiente escolar que pertencem.

Tanto a equipe pedagógica quanto a direção elogiou o trabalho e pediu para que levassem estes dados para as salas de aula e também para uma reunião pedagógica posterior. Este reconhecimento da importância da atividade contribuiu significativamente para que os estudantes pudessem perceber o valor do trabalho que realizaram e das contribuições que poderiam fazer.

Cada grupo teve a oportunidade de ir até a turma, que foi seu objeto de estudo, explicar os resultados que encontraram tanto na conscientização do que já era claro, quanto na questão de propor melhorias para as próximas notas, utilizando para isso os gráficos que construíram na oficina.

Uma das falas que marcou muito a professora durante uma destas explicações, foi quando um estudante que não havia feito a oficina questionou se ela iria acontecer novamente, dizendo que queria participar, pois havia achado interessante o trabalho que o grupo estava apresentando.

Após todas as intervenções nas salas de aula e término da oficina, um dos estudantesfez o seguinte comentário, que marcou muito a pesquisadora:

$\mathrm{E}_{8}$ : Professora quando vai ter mais?

Professora: Acho que agora só ano que vem!

E: Mas nós somos prioridades né, já que fizemos este ano.

Professora: Pode deixar que quando houver outra oficina, vocês serão convidados.

Esta fala de $\mathrm{E}_{8}$ fez a professora perceber que realmente os estudantes se sentiram entusiasmados e determinados a continuar estudando, motivando até mesmo estudantes que não estavam participando, como foi o caso do estudante que questionou quando a oficina aconteceria novamente. Pode-se perceber durante todo o trabalho, que a utilização de dados do contexto escolar ao qual pertencem e esta proposta de intervenção final

\footnotetext{
${ }^{6} \mathrm{Na}$ escola analisada, as notas são atribuídas de 0 à 10,0 e notas abaixo de 6,0 são consideradas abaixo da média.
} 
contribuíram para que os estudantes pudessem perceber a importância do trabalho que estavam realizando e deram utilidade para o mesmo.

\section{CONSIDERAÇÕES FINAIS}

O trabalho de pesquisar a própria prática ganhou relevância segundo Bortoni-Ricardo (2008) por proporcionar à interação professor-aluno e desenvolver uma maior a qualidade no processo de aprendizagem. Frente a isso, os professores que buscam investigar a própria prática, estão buscando encontrar meios de apresentar conteúdos e acompanhar da aprendizagem dos estudantes de forma diferente das que utilizam usualmente.

No presente artigo, pode-se perceber, com base nos resultados obtidos durante o processo, que havendo a interação teoria e prática é possível contribuir tanto para o aprendizado dos estudantes quanto para a mudança da metodologia docente utilizada.

É importante destacar que o professor tem inúmeros saberes relacionados a prática docente, sendo necessário que alguns deles precisem ser aprimorados ou adquiridos para uma pratica educativo-crítica, Freire (1996). Cabe destacar que quando o professor planeja uma ação levando em conta os saberes, consegue estimular e motivar os estudantes durante todo o processo de ensino.

$\mathrm{Na}$ oficina buscou-se levar em consideração os diversos saberes necessários a docência, da escolha do tema até as atividades propostas e o meio de condução das mesmas. Optou-se por estatística tanto por estar presente nos PCNs e nas Orientações Curriculares, quanto por possibilitar que os estudantes pudessem criar hipóteses, tirar conclusões e ainda intervirem no meio escolar.

De fato, pode-se perceber que durante o processo de ensino os estudantes tiveram motivação e viram significado para o conteúdo que estavam aprendendo, construíram os conceitos a partir de seus conhecimentos prévios e tiveram a oportunidade de expor no grupo suas ideias e pensamentos.

Outro fato de destaque foi a possibilidade de, a partir dos resultados obtidos, terem embasamento para proporem melhorias no ambiente escolar, nas salas de aulas e junto à equipe pedagógica. Esta teve um papel importantíssimo neste processo, pois transmitiu confiança aos estudantes e os fez perceber o quanto o trabalho que estavam realizando era relevante.

Concluindo, a professora pesquisadora pôde verificar o quanto mudanças, muitas vezes simples, podem melhorar a prática didática. É necessário, portanto, estimular os estudantes a pensar, a expor suas compreensões e perderem o medo de errar, se isso for possível, consequentemente, eles terão um aprendizado mais prazeroso, marcante e, ao mesmo tempo, decisivo dentro do processo de assimilação do conhecimento.

\section{REFERÊNCIAS}

ALSINA I PASTELLS, Ángel. Desenvolvimento de competências matemáticas com recursos lúdicos-manipulativos. Curitiba: Base Editorial, 2009.

BICUDO, M. A. V. Educação Matemática. São Paulo: Editora Moraes, 2005.

BONDIA. J.L. Notas sobre a experiência e o saber de experiência. Campina: Revista Brasileira de Educação, n.19, p. 20-28, 2002. 
BORTONI-RICARDO. S.M. O professor pesquisador: introdução a pesquisa qualitativa. São Paulo: Parábola Editorial, 2008.

BRASIL. Mistério da Educação. Secretaria da Educação Básica. Orientações curriculares para o ensino médio. Vol. 2. Brasília: 2006.

BRASIL. Ministério da Educação. Secretaria de Educação Média e Tecnológica. Parâmetros Curriculares Nacionais (Ensino Médio). Brasília: MEC, 2000.

FREIRE, Paulo. Pedagogia da autonomia: saberes necessários à prática educativa. São Paulo: Paz e Terra, 1996.

FREIRE, Paulo. HORTON, Myles. O caminho se faz caminhando: conversas sobre educação e mudança social. Petrópolis: Vozes, 2003.

LAKATOS, Eva Maria. Fundamentos de metodologia científica. 5. ed. São Paulo: Atlas, 2003.

LÜDKE, Menga. ANDRÉ, Marli E. D. A. Pesquisa em educação: abordagens qualitativas. 2. ed. Rio de Janeiro: EPU, 2013.

MORAN. José Manuel. MASETTO. Marcos T. BEHRENS. Marilda Aparecida. Novas tecnologias e mediação pedagógica. 21. ed. Campinas: Papirus, 2013.

MOREIRA, Marco Antonio. Teorias de aprendizagem. São Paulo: EPU, 1999.

NEVES, Rita de Araujo. DAMIANI, Magda Floriana. Vygotsky e as teorias da aprendizagem. UNIrevista - Vol. 1, n². Universidade Federal de Pelotas, RS, 2006.

PARANÁ. Secretaria da Educação. Diretrizes Curriculares de Matemática para a Educação Básica. Curitiba: SEED, 2008.

PONTE, J.P. Pesquisar para compreender e transformar a nossa própria pratica. Educar em Revista, 24, 37-66, 2004.

PRODANOV, Cleber Cristiano. FREITAS, Ernani Cesar de. Metodologia do trabalho científico: métodos e técnicas da pesquisa e do trabalho acadêmico. 2. ed. Novo Hamburgo: Feevale, 2013.

TARDIF, Maurice. Saberes docentes e formação profissional. 15. ed. Petrópolis: Vozes, 2013. TIBA, Içami. Ensinar Aprendendo: como superar os desafios do relacionamento professoraluno em tempos de globalização. São Paulo: Editora Gente, 1998. 